\title{
Posterior Sublaminar Wiring and/or Transarticular Screw Fixation for Reducible Atlantoaxial Instability Secondary to Symptomatic Os Odontoideum: A Neglected Technique?
}

\author{
Han Chang ${ }^{1}$, Jong-Beom Park ${ }^{2}$, Byung-Wan Choi ${ }^{3}$, Jong-Won Kang ${ }^{4}$, You-Seung Chun ${ }^{2}$ \\ ${ }^{1}$ Department of Orthopedic Surgery, Busan Korea Hospital, Busan, Korea \\ ${ }^{2}$ Department of Orthopedic Surgery, College of Medicine, The Catholic University of Korea, Seoul, Korea \\ ${ }^{3}$ Department of Orthopedic Surgery, Inje University Haeundae Paik Hospital, Busan, Korea \\ ${ }^{4}$ Department of Orthopedic Surgery, Sun Hospital, Daejeon, Korea
}

\section{Study Design: Retrospective case analysis.}

Purpose: We retrospectively evaluated the clinical and radiological outcomes of posterior sublaminar wiring (PSLW) and/or transarticular screw fixation (TASF) for reducible atlantoaxial instability (AAl) secondary to os odontoideum.

Overview of Literature: Limited information is available about the surgical outcomes of symptomatic os odontoideum with AAI.

Methods: We examined 23 patients (12 women and 11 men) with os odontoideum and reducible AAI. The average age of the patients at the time of the operation was 44.2 years. The average follow-up duration was 4.5 years. Thirteen patients with anterior AAI underwent PSLW alone, while 10 patients with combined (anterior+posterior) AAI underwent PSLW and TASF. An autogenous iliac bone graft was used for all patients. Nine patients complained of neck or suboccipital pain, and 14 complained of myelopathy. Results: Angulational instability (preoperative $18.7^{\circ} \pm 8.9^{\circ}$ vs. postoperative $2.1^{\circ} \pm 4.6^{\circ}, p<0.001$ ), translational instability $(16.3 \pm 4.9 \mathrm{~mm}$ vs. $1.8 \pm 2.2 \mathrm{~mm}, p<0.001)$, and segmental angle of the $\mathrm{C} 1-\mathrm{C} 2$ joint $\left(23.7^{\circ} \pm 7.2^{\circ}\right.$ vs. $\left.28.4^{\circ} \pm 3.8^{\circ}, p<0.05\right)$ showed significant improvement postoperatively. Neck Visual Analog Scale score $(6.2 \pm 2.4$ vs. $2.5 \pm 1.8, p<0.05)$ and the modified Japanese Orthopedic Association (9.1 \pm 3.1 vs. $13.2 \pm 2.6, p<0.05)$ score also improved, with a recovery rate of $51.8 \%$. Among the three patients who developed nonunion and/or wire breakage, one underwent revision surgery with repeat PSLW and was finally able to achieve fusion. The final fusion rate was $91.3 \%$.

Conclusions: PSLW and/or TASF provided satisfactory clinical and radiological outcomes in reducible AAl secondary to os odontoideum without significant neurological complications. Our results suggest that PSLW and/or TASF can be considered a viable surgical option over segmental fixation in highly selected cases of os odontoideum with reducible AAI.

Keywords: Os odontoideum; Atlantoaxial instability; Posterior sublaminar wiring; Transarticular fixation

Received Jul 3, 2018; Revised Aug 13, 2018; Accepted Aug 16, 2018

Corresponding author: Jong-Beom Park

Department of Orthopaedic Surgery, Uijeongbu St. Mary’s Hospital, College of Medicine, The Catholic University of Korea, 271 Cheonbo-ro, Uijeongbu 11765, Korea

Tel: +82-31-820-3578, Fax: +82-31-847-3671, E-mail: spinepjb@catholic.ac.kr 


\section{Introduction}

Os odontoideum is a rare disease that leads to atlantoaxial instability (AAI). Os odontoideum is defined as an ossicle with smooth circumferential cortical margins representing the odontoid process that has no osseous continuity with the body of C2 [1]. The natural history of untreated os odontoideum can show considerable variation, and there is limited information available to make the decision regarding the treatment options. Indication for surgical treatment can simply be the existence of an os odontoideum, in association with occipital cervical pain alone or in association with neurological symptoms and signs [1-4]. Other factors that help in establishing the need for stabilization and/or decompression include C1-C2 instability, associated deformities, and spinal cord compression. Few studies have reported on the surgical outcomes of symptomatic os odontoideum with AAI. Several techniques have been utilized to stabilize $\mathrm{C} 1$ and $\mathrm{C} 2$ in os odontoideum patients [1,3-14]. The surgical treatment of patients with $\mathrm{C} 1-\mathrm{C} 2$ instability secondary to os odontoideum is demonstrated to be successful when combined fusion and internal fixation techniques are used. Posterior sublaminar wiring (PSLW) and/or transarticular screw fixation (TASF) have been widely used as surgical options; however, majority of previous studies included only few patients with os odontoideum $[5,7,12,14]$. Although the numbers are small, rigid C1-C2 internal fixation and fusion (e.g., with transarticular screw, C1-C2 screw/rod construct, or C1 hook/C2 screw construct, etc.) are associated with higher

Table 1. Demographic data of 23 patients

\begin{tabular}{|c|c|c|c|c|c|c|}
\hline \multirow[b]{2}{*}{$\begin{array}{l}\text { Patient } \\
\text { no. }\end{array}$} & \multirow[b]{2}{*}{$\begin{array}{l}\text { Sex/age } \\
\text { (yr) }\end{array}$} & \multirow[b]{2}{*}{$\begin{array}{l}\text { Clinical } \\
\text { symptoms }\end{array}$} & \multicolumn{2}{|c|}{ Magnetic resonance imaging findings } & \multirow[b]{2}{*}{$\begin{array}{l}\text { Direction of } \\
\text { instability }\end{array}$} & \multirow[b]{2}{*}{ Surgery } \\
\hline & & & $\begin{array}{l}\text { Retro-dental reactive } \\
\text { lesions }\end{array}$ & $\begin{array}{l}\text { Intramedullary high } \\
\text { signal intensity }\end{array}$ & & \\
\hline 1 & $\mathrm{~F} / 50$ & Myelopathy & Fibrocartilaginous & + & Ant+Post & TASF+PAAW \\
\hline 2 & $F / 43$ & Myelopathy & Cystic & + & Ant+Post & TASF+PAAW \\
\hline 3 & $\mathrm{~F} / 44$ & Neck pain & & & Ant & PAAW \\
\hline 4 & $F / 49$ & Neck pain & & & Ant & PAAW \\
\hline 5 & $F / 61$ & Myelopathy & Fibrocartilaginous & + & Ant+Post & TASF+PAAW \\
\hline 6 & $F / 47$ & Myelopathy & Fibrocartilaginous & + & Ant+Post & TASF+PAAW \\
\hline 7 & $F / 63$ & Neck pain & & & Ant & PAAW \\
\hline 8 & $M / 36$ & Neck pain & & & Ant & PAAW \\
\hline 9 & $\mathrm{M} / 44$ & Myelopathy & Fibrocartilaginous & + & Ant+Post & TASF+PAAW \\
\hline 10 & $M / 26$ & Myelopathy & Fibrocartilaginous & + & Ant & PAAW \\
\hline 11 & $\mathrm{M} / 43$ & Neck pain & & & Ant & PAAW \\
\hline 12 & $\mathrm{~F} / 44$ & Myelopathy & Fibrocartilaginous & + & Ant & PAAW \\
\hline 13 & $M / 5$ & Neck pain & & & Ant & PAAW \\
\hline 14 & $\mathrm{~F} / 46$ & Neck pain & & & Ant+Post & TASF+PAAW \\
\hline 15 & $M / 64$ & Myelopathy & Fibrocartilaginous & + & Ant+Post & TASF+PAAW \\
\hline 16 & $F / 59$ & Neck pain & & & Ant & PAAW \\
\hline 17 & $M / 54$ & Myelopathy & Fibrocartilaginous & + & Ant+Post & TASF+PAAW \\
\hline 18 & $\mathrm{M} / 42$ & Myelopathy & Cystic & + & Ant+Post & TASF+PAAW \\
\hline 19 & $F / 11$ & Neck pain & & & Ant & PAAW \\
\hline 20 & $M / 45$ & Myelopathy & Fibrocartilaginous & + & Ant & PAAW \\
\hline 21 & $F / 19$ & Myelopathy & Fibrocartilaginous & + & Ant & PAAW \\
\hline 22 & $M / 47$ & Myelopathy & Cystic & + & Ant & PAAW \\
\hline 23 & $\mathrm{M} / 73$ & Myelopathy & Fibrocartilaginous & + & Ant+Post & TASF+PAAW \\
\hline
\end{tabular}

F, female; M, male; Ant, anterior; Post, posterior; TASF, trans-articular screw fixation using Magerl's technique; PAAW, posterior atlantoaxial wiring. 
rates of fusion than posterior wiring and fusion techniques alone. Harms et al. [15] reported C1 lateral mass and $\mathrm{C} 2$ pedicle screw fixation; thereafter, most $\mathrm{C} 1-\mathrm{C} 2$ stabilization procedures were shifted to $\mathrm{C} 1-\mathrm{C} 2$ segmental screw fixation. Although this technique provides rigid stabilization, there exists a risk of complications, and the method is technically demanding. PSLW is considered old fashioned and is currently avoided. The earliest reports of PSLW for surgical treatment of os odontoideum describe a small pediatric case series. Therefore, we retrospectively evaluated the clinical and radiological outcomes of PSLW and/or TASF for reducible AAI secondary to os odontoideum.

\section{Materials and Methods}

We retrospectively analyzed 23 patients (12 women and 11 men) who had os odontoideum with reducible AAI, underwent posterior fusion, and were followed up for at least 24 months (Table 1). The mean age at the time of the operation was 44.2 years (range, 5-73 years), and the mean follow-up duration was 4.5 years (range, 2-12 years). Nine patients complained of neck or suboccipital pain, and 14 complained of myelopathy. All the patients with myelopathy showed intramedullary signal change and retrodental reactive lesions (three cystic and 11 fibrocartilaginous lesions) on magnetic resonance imaging (MRI). MRI was performed using a 1.5-tesla Siemens unit (Siemens, Erlangen, Germany) in 14 patients with myelopathy.

The direction of C1-C2 instability was defined as the direction of displacement of the spinolaminar line during

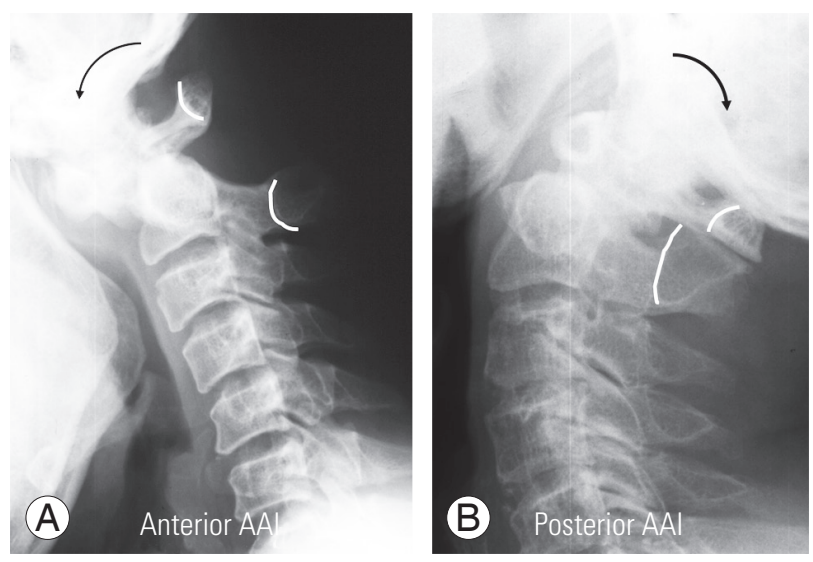

Fig. 1. (A, B) The direction of instability was defined as the direction of displacement of the spinolaminar line during flexion and extension. AAl, atlantoaxial instability. flexion and extension (Fig. 1). Plain anteroposterior and lateral radiographs were taken before the procedure and at the final follow-up in the upright neutral, flexion, and extension positions. We analyzed the angular instability, translational instability, and segmental angle of the $\mathrm{C} 1-\mathrm{C} 2$
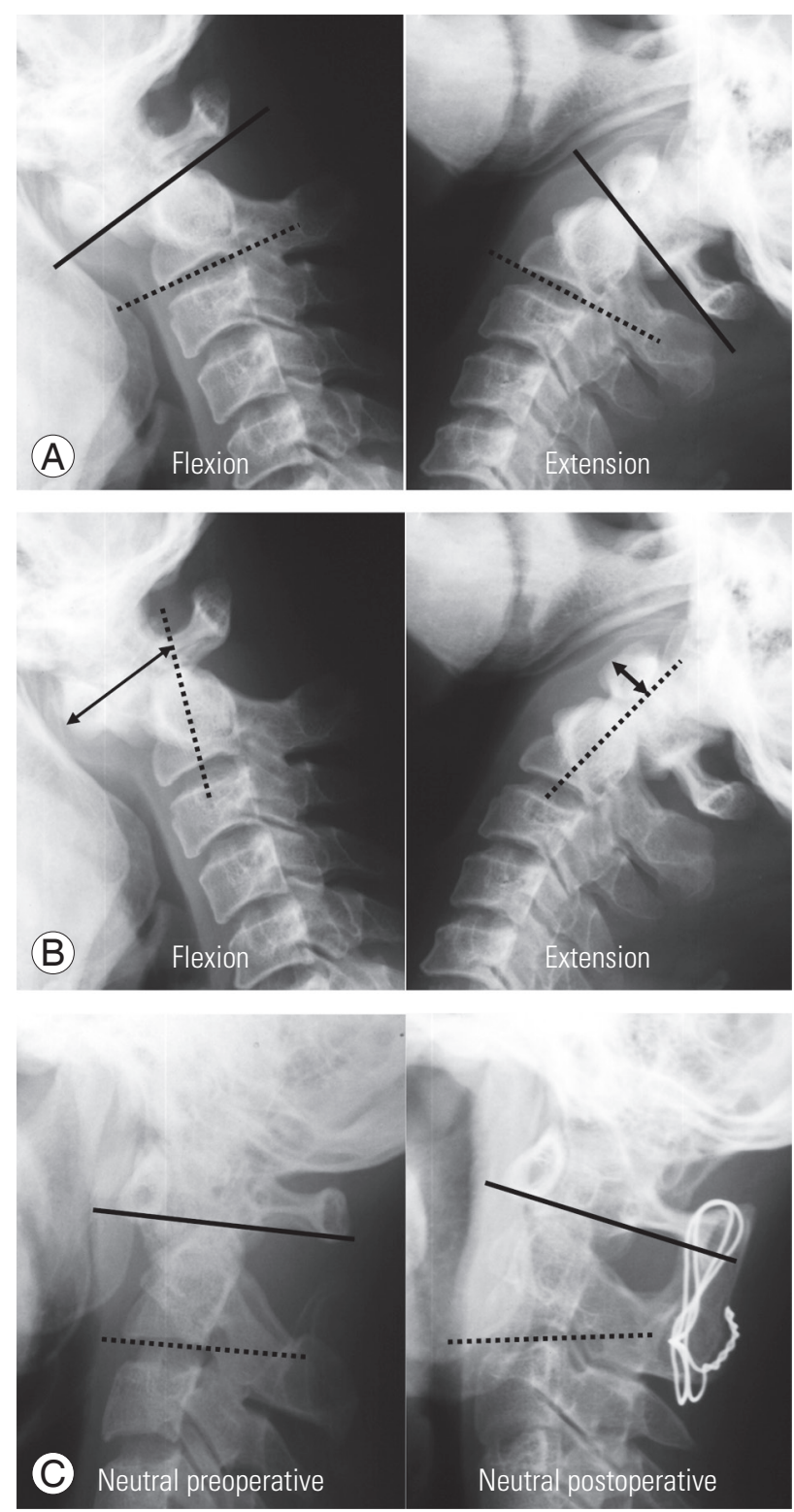

Fig. 2. Radiological measurements of angular instability (A), translational instability (B), and C1-C2 segmental angle (C). (A) Angular instability was analyzed using the difference in the C1-C2 angle on flexion and extension lateral radiographs. (B) The degree of translational instability was defined as the maximum distance that the os odontoideum moves in the sagittal plane during flexion and extension. (C) The segmental angle was measured between the line passing through the centers of the $\mathrm{C} 1$ anterior and the posterior arches and the line tangential to the inferior border of the C2 body on neutral lateral radiograph. 
joint that were measured using a standard tube distance of 6 feet $(1.8 \mathrm{~m})$. Angular instability was analyzed using the difference in the $\mathrm{C} 1-\mathrm{C} 2$ angle on flexion and extension lateral radiographs (Fig. 2A). The degree of translational instability was defined as the maximum distance that the os odontoideum moves in the sagittal plane during flexion and extension (Fig. 2B). The segmental angle was measured between the line passing through the centers of the $\mathrm{C} 1$ anterior and posterior arches and the line tangential to the inferior border of the $\mathrm{C} 2$ body on neutral lateral radiograph (Fig. 2C). The criteria for bone fusion were as follows: (1) difference $<2^{\circ}$ between the flexed and extended lateral radiographs, (2) formation of a bony bridge, (3) no findings of implant failure, and (4) radiolucency in $<50 \%$ of the tissue around the implant [16].

All the surgeries were performed by a single senior spine surgeon. Thirteen patients with anterior AAI underwent PSLW alone (Fig. 3), while 10 patients with combined (anterior+posterior) AAI underwent PSLW and TASF (Fig. 4). Autogenous iliac bone graft was used for all patients. The surgical procedures were briefly described to the patients. The patients were asked to be in the prone position with the skull fixed with a Mayfield clamp. The
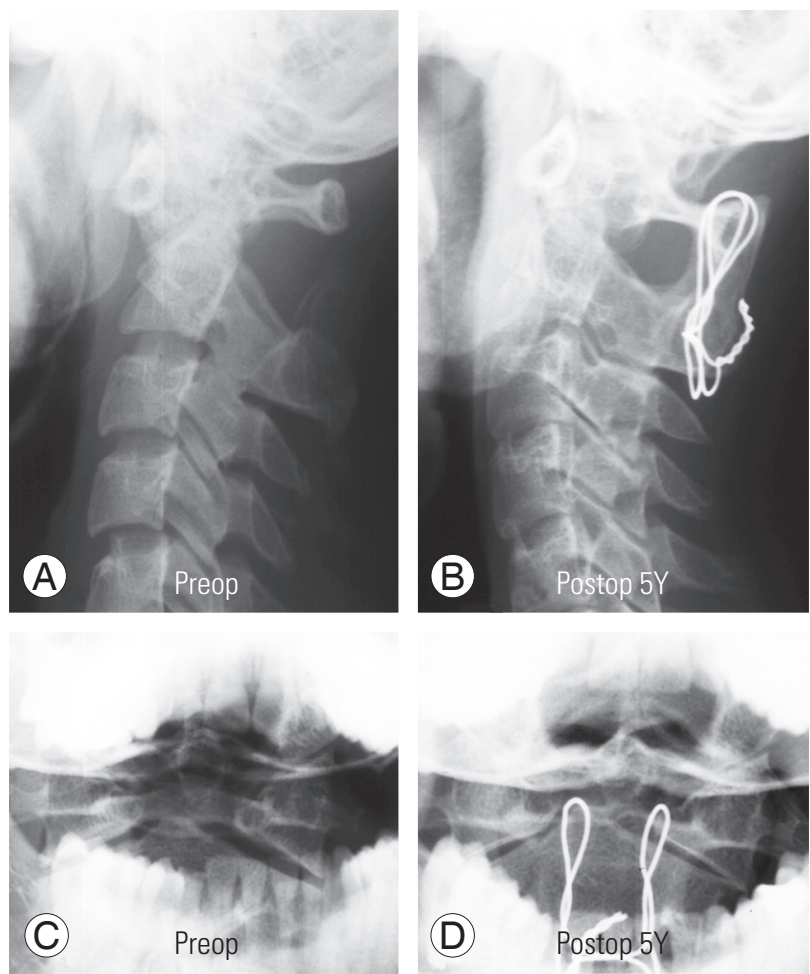

Fig. 3. (A-D) A representative case of posterior sublaminar wiring only; excellent fusion and clinical results at the 5-year follow-up. Preop, preoperative; Postop, postoperative. neck was positioned to optimize access by providing slight flexion at the occiput while extending the subaxial spine. An attempt was made to reduce $\mathrm{C} 1-\mathrm{C} 2$ articulation during this positioning process. The procedures were assisted with fluoroscopy. A midline incision was made over $\mathrm{C} 1-\mathrm{C} 2$ but extended distally to allow the required drill angulation; the posterior aspects of $\mathrm{C}-1$ and $\mathrm{C}-2$ were fully exposed. Subperiosteal exposure of the $\mathrm{C} 1$ arch and $\mathrm{C} 2$ posterior elements was performed. Cannulated screws were placed for bilateral transarticular fixation under lateral fluoroscopic guidance $[3,5]$. Following screw placement, the Gallie wiring method was used for fixing an iliac bone graft [17]. A postoperative Philadelphia collar was applied for patients who underwent both procedures for 6-12 weeks to facilitate fusion.

The operative results were estimated as per the degree
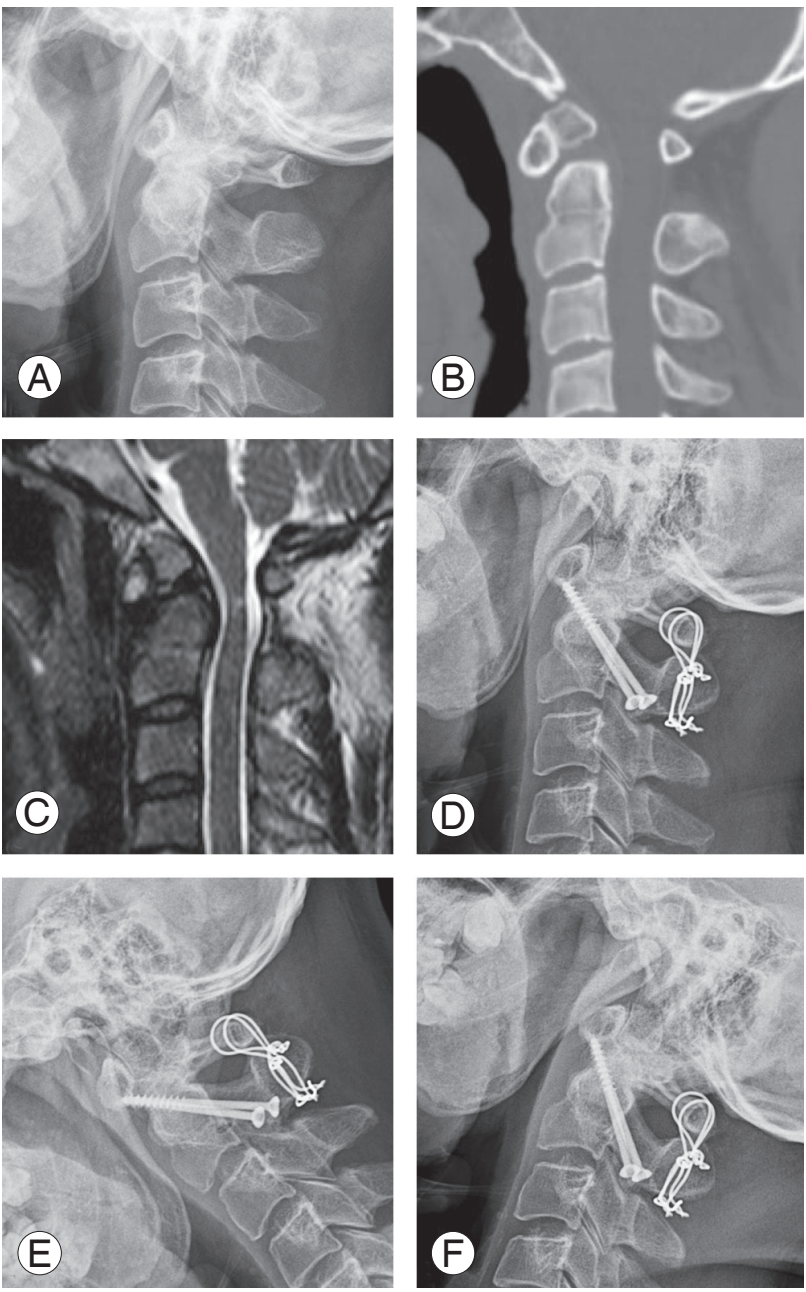

Fig. 4. (A-F) A representative case of posterior sublaminar wiring with transarticular screw fixation; excellent fusion and clinical results at the 12-year follow-up. 
Table 2. Radiological outcomes of posterior sublaminar wiring and/or transarticular screw fixation for atlantoaxial instability secondary to os odontoideum

\begin{tabular}{lccc} 
& Preoperative & Last follow-up & $p$-value \\
\hline Angulational instability $\left({ }^{\circ}\right)$ & $18.7 \pm 8.9$ & $2.1 \pm 4.6$ & $<0.001$ \\
\hline Translational instability $(\mathrm{mm})$ & $16.3 \pm 4.9$ & $1.8 \pm 2.2$ & $<0.001$ \\
\hline C1-C2 segmental angle $\left({ }^{\circ}\right)$ & $23.7 \pm 7.2$ & $28.4 \pm 3.8$ & $<0.05$ \\
\hline
\end{tabular}
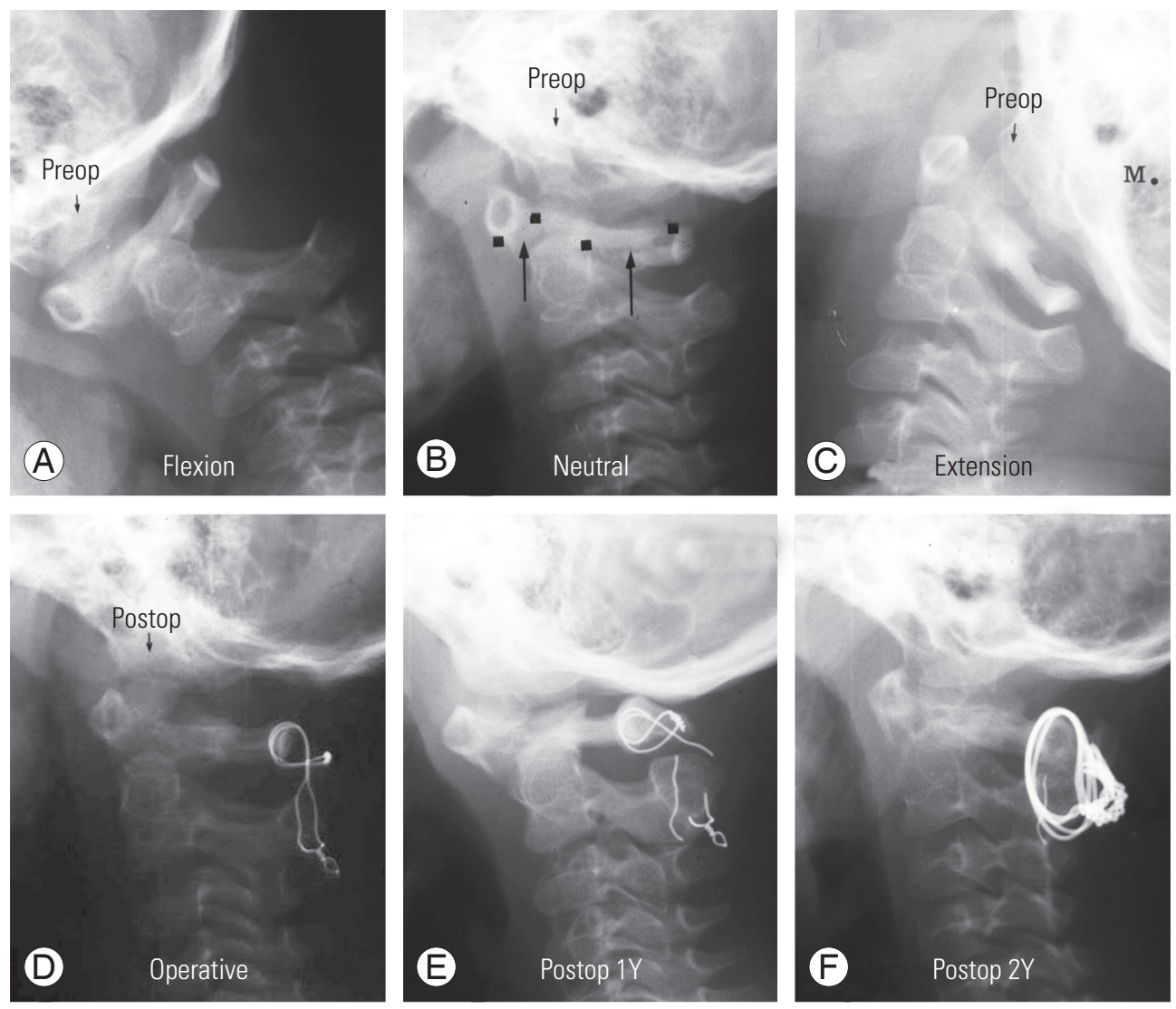

Fig. 5. (A-F) A 6-year-old female patient with PSLW because of atlantoaxial instability with os odontoideum. The 1-year follow-up showed nonunion and wire breakage. Revision with the same PSLW showed complete union at the 2-year follow-up after revision. PSLW, posterior sublaminar wiring; Preop, preoperative; Postop, postoperative.

of improvement in the neck Visual Analog Scale (VAS) and the modified Japanese Orthopedic Association (JOA) score with a recovery rate that was established by the JOA to evaluate the operative results in patients with cervical myelopathy [18]. The paired $T$-test was used to determine statistically significant differences between the preoperative and final follow-up data. Statistical significance was set at $p<0.05$. This retrospective study was approved by the Institutional Review Board of the Uijeongbu St. Mary's Hospital (e-IRB UC17RESI0145) and informed consent was waived.

\section{Results}

The results for the radiographic parameters are listed in Table 2. Angulational instability, translational instability, and segmental angle of the $\mathrm{C} 1-\mathrm{C} 2$ joint showed significant postoperative improvement. The neck VAS $(6.2 \pm 2.4$ versus $2.5 \pm 1.8, p<0.05)$ and the modified JOA $(9.1 \pm 3.1$ versus $13.2 \pm 2.6, p<0.05)$ score also improved, with a recovery rate of $51.8 \%$. Twenty patients achieved solid C1C2 fusion successfully; however, three patients (13\%) developed nonunion and/or wire breakage. Among them, 

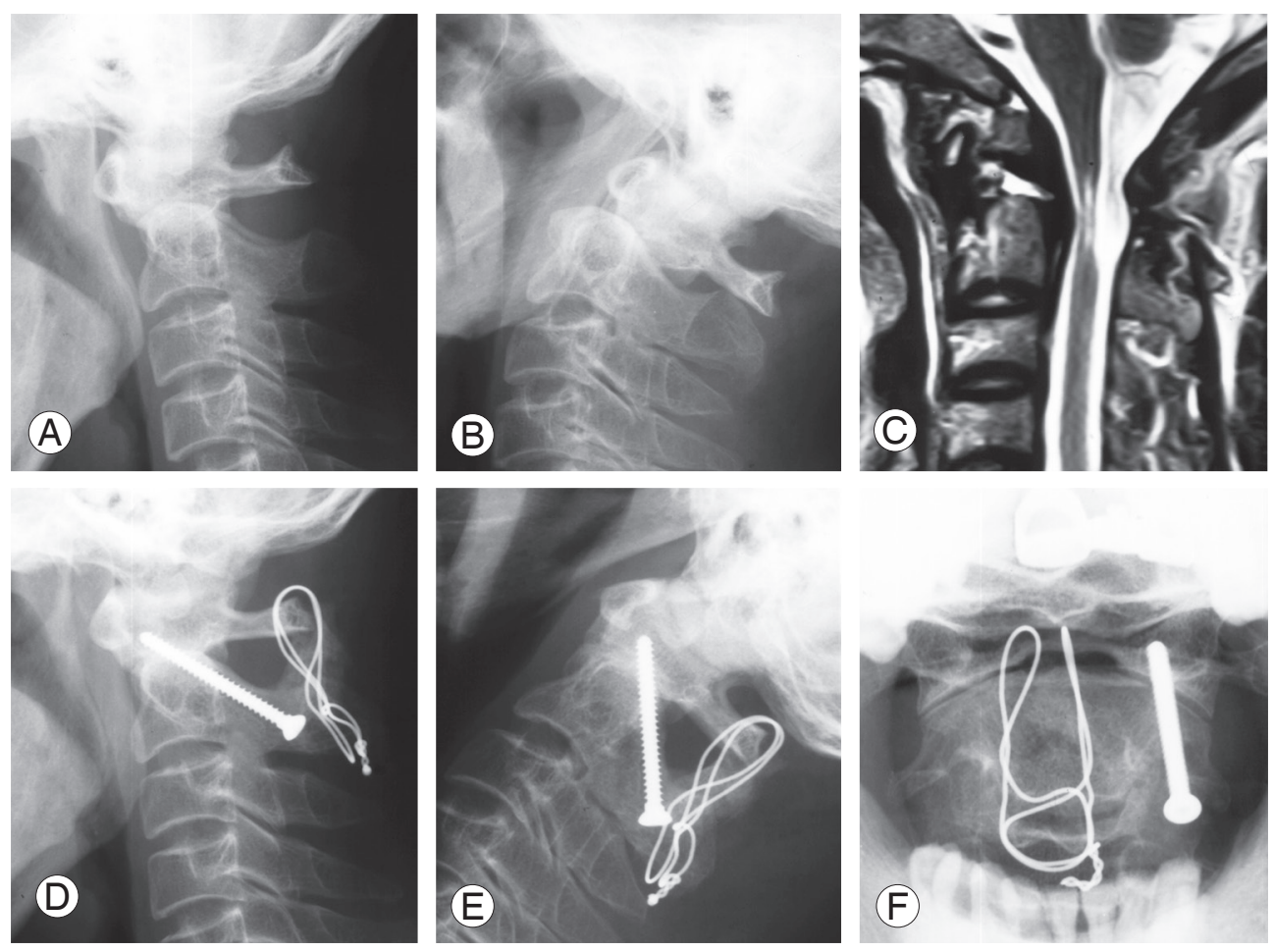

Fig. 6. (A-F) A 37-year-old male patient who had posterior sublaminar wiring with transarticular screw fixation because of cervical myelopathy caused by atlantoaxial instability. During the operation, a right-side vertebral artery injury occurred. Intraoperative bleeding was successfully managed with packing of bone wax. He showed no neurological distortion during follow-up.

one underwent revision surgery with repeat PSLW and finally achieved fusion (Fig. 5). The final fusion rate was 91.3\% (in 21 of the 23 patients). One patient experienced vertebral artery injury during TASF; however, this was successfully managed with packing of bone wax (Fig. 6). There were no neurological complications in any patient.

\section{Discussion}

Atlantoaxial articulation is a unique process. Its full range of motion in the spine is dependent on ligamentous support and the integrity of the odontoid for stability. The etiology of AAI includes trauma, congenital malformations, os odontoideum, rheumatoid arthritis, malignancies, and skeletal dysplasia. Os odontoideum is an anomaly that is defined as an ossicle with smooth circumscribed margins and no osseous continuity with the $\mathrm{C} 2$ body $[1,2,4,9,19,20]$. Os odontoideum with AAI can be asymptomatic or have several symptoms, including occipitocervical pain alone, myelopathy or intracranial symptoms, or signs of vertebrobasilar ischemia [19]. Clinically, patients experience severe neck pain and myelopathy resulting from craniocervical instability and spinal cord compression. Nine of the 23 patients in our study complained of neck or suboccipital pain, and 14 complained of myelopathy.

Currently, there is limited evidence to support the management standards and guidelines in the treatment of os odontoideum. The surgical techniques used to treat os odontoideum range from sublaminar wiring to segmental screw fixation. The early surgical techniques of Brooks and Jenkins [21] and Gallie [17] described various fusion results. Biomechanically, movement is limited in this type of fusion in extension (strut or bone graft) and flexion (sublaminar wires or transarticular screws). Most advocates of this surgical approach recommend postoperative halo immobilization for three months. These techniques also require a normal posterior arch of $\mathrm{C} 1$ and $\mathrm{C} 2$ that may not be present in cases of congenital anomalies.

Lowry et al. [22] described a $20 \%$ non-union rate with Brooks-Jenkins type sublaminar wiring technique in os odontoideum patients. In order to achieve successful fusion, it is necessary to perform stability reconstruction between $\mathrm{C} 1$ and $\mathrm{C} 2$ combined with bone grafting. TASF 
with strut grafts and polyaxial screw fixation reportedly show better fusion rates than the sublaminar wiring technique. Dickman and Sonntag [23] showed a 98\% fusion rate with this technique compared to $86 \%$ with PSLW in a large series of 121 patients, nine of whom had os odontoideum. In contrast, Farey et al. [24] showed a 33\% nonunion rate using the Gallie technique with immobilization versus $100 \%$ when using arthrodesis with TASF screws in 27 patients, six of whom had os odontoideum. Several other studies have also shown good fusion with this technique [25].

PSLW alone was performed in 13 cases, while PSLW and TASF were performed for 10 patients. PSLW alone was used for anterior AAI cases, and PSLW and TASF were preferred in combined AAI cases. We found a 91.3\% fusion rate. The neck VAS and the modified JOA score also improved, with a recovery rate of $51.8 \%$. We recommend additional TASF in combined anterior and posterior instability; however, only posterior wiring is sufficient in anterior instability cases if preoperative reduction is possible.

The latest generation of posterior spinal instrumentation is the polyaxial screw-rod system. This approach has been used for atlantoaxial fusion by Harms and Melcher [15] in a series on six os odontoideum patients. Although there appears to be no significant difference in the fusion rates between the transarticular screw and pedicle/lateral mass combinations, the polyaxial screws are secured to the rods, fixation and reduction are achieved. In addition, this system can be used as an alternative to TASF that is unsuitable in cases with a short neck, exaggerated cervicothoracic kyphosis, morbid obesity, or a high-riding vertebral artery. The atlantoaxial joint must be aligned before TASF for achieving good reduction. One of the most important advantages of the polyaxial screw-rod system is that $\mathrm{C} 1-\mathrm{C} 2$ joint reduction can be achieved intraoperatively when preoperative reduction cannot achieved by the intraoperative positioning process. However, os odontoideum is usually reducible by intraoperative positioning only. We can also achieve reduction by simple manual compression of the $\mathrm{C} 2$ spinous process in cases wherein reduction is not achieved via intraoperative positioning.

About one-fifth of the patients with craniovertebral junction abnormalities have vertebral artery and/or osseous anomalies; this increases the risk of vertebral artery injury with the TASF technique than with segmental fixation. However, the risk of vertebral artery injury with polyaxial screws appears to be comparable to that reported for TASF, primarily because of aberrant vertebral artery anatomy [26]. In our study, one patient with TASF had vertebral artery injury; this patient was managed with simple packing of bone wax without any neurological complications. A malpositioned screw does not always lead to vertebral injury. Vertebral injury caused by a perforated pedicle screw in the transverse foramen is rare. Sanelli et al. [27] showed that in $34 \%$ of the cases, the vertebral artery enters the transverse foramen at $\mathrm{C} 2$. There is a relative 'abundance space' for the vertebral artery in the transverse foramen, further, not all violations of the transverse foramen damage the vertebral artery. Yukawa et al. [28] showed that 57 screws were of type 2, and 24 screws were of type 3 . There was only one penetration of a probe into the vertebral artery. The type 3 misplacement indicated potential risk for neurovascular injury. Screw placement is sometimes technically challenging owing to the complex anatomic relationships of bony, vascular, and neurological structures. In such cases, segmental fixations lead to injury of the vertebral artery. If the os odontoideum has anterior AAI, only PSLW is sufficient for reduction and bony fusion as our cases without the risk of vertebral artery injury. Our results showed excellent postoperative radiological and clinical results of PSLW in highly selected cases of reducible AAI secondary to os odontoideum. PSLW remains one of the optimal approaches.

This study has certain limitations. First, it is a retrospective case series with a relatively lower number of patients because this pathologic condition is uncommon. Second, we did not employ a control group for comparison, such as patients undergoing $\mathrm{C} 1-\mathrm{C} 2$ polyaxial screw fixation. However, to our knowledge, no previous studies have evaluated more than 20 cases of os odontoideum, especially using the traditional PSLW and/or TASF techniques.

\section{Conclusions}

PSLW and/or TASF provided satisfactory clinical outcomes in reducible AAI secondary to os odontoideum, with fusion rates similar to those of segmental fixation, without significant neurological complications. Our results suggest that PSLW and/or TASF can be considered viable surgical options over segmental fixation in highly selected cases of os odontoideum with reducible AAI. 


\section{Conflict of Interest}

No potential conflict of interest relevant to this article was reported.

\section{References}

1. Spierings EL, Braakman R. The management of os odontoideum: analysis of 37 cases. J Bone Joint Surg Br 1982;64:422-8.

2. Klimo P Jr, Kan P, Rao G, Apfelbaum R, Brockmeyer D. Os odontoideum: presentation, diagnosis, and treatment in a series of 78 patients. J Neurosurg Spine 2008;9:332-42.

3. Reilly CW, Choit RL. Transarticular screws in the management of $\mathrm{C} 1-\mathrm{C} 2$ instability in children. J Pediatr Orthop 2006;26:582-8.

4. Zhang Z, Zhou Y, Wang J, et al. Acute traumatic cervical cord injury in patients with os odontoideum. J Clin Neurosci 2010;17:1289-93.

5. Gluf WM, Schmidt MH, Apfelbaum RI. Atlantoaxial transarticular screw fixation: a review of surgical indications, fusion rate, complications, and lessons learned in 191 adult patients. J Neurosurg Spine 2005;2:155-63.

6. Ni B, Zhu Z, Zhou F, et al. Bilateral C1 laminar hooks combined with $\mathrm{C} 2$ pedicle screws fixation for treatment of C1-C2 instability not suitable for placement of transarticular screws. Eur Spine J 2010;19:1378-82.

7. Brockmeyer DL, York JE, Apfelbaum RI. Anatomical suitability of C1-2 transarticular screw placement in pediatric patients. J Neurosurg 2000;92(1 Suppl):7-11.

8. Coyne TJ, Fehlings MG, Wallace MC, Bernstein M, Tator CH. C1-C2 posterior cervical fusion: longterm evaluation of results and efficacy. Neurosurgery 1995;37:688-92.

9. Wang J, Vokshoor A, Kim S, Elton S, Kosnik E, Bartkowski H. Pediatric atlantoaxial instability: management with screw fixation. Pediatr Neurosurg 1999;30:70-8.

10. Lu G, Passias PG, Li G, et al. Endoscopically assisted anterior release and reduction through anterolateral retropharyngeal approach for fixed atlantoaxial dislocation. Spine (Phila Pa 1976) 2010;35:544-51.

11. Haque A, Price AV, Sklar FH, Swift DM, Weprin BE, Sacco DJ. Screw fixation of the upper cervical spine in the pediatric population: clinical article. J Neurosurg Pediatr 2009;3:529-33.

12. Visocchi M, Fernandez E, Ciampini A, Di Rocco C. Reducible and irreducible os odontoideum in childhood treated with posterior wiring, instrumentation and fusion: past or present? Acta Neurochir (Wien) 2009;151:1265-74.

13. Chamoun RB, Relyea KM, Johnson KK, et al. Use of axial and subaxial translaminar screw fixation in the management of upper cervical spinal instability in a series of 7 children. Neurosurgery 2009;64:734-9.

14. Gluf WM, Brockmeyer DL. Atlantoaxial transarticular screw fixation: a review of surgical indications, fusion rate, complications, and lessons learned in 67 pediatric patients. J Neurosurg Spine 2005;2:164-9.

15. Harms J, Melcher RP. Posterior C1-C2 fusion with polyaxial screw and rod fixation. Spine (Phila $\mathrm{Pa}$ 1976) 2001;26:2467-71.

16. Kandziora F, Pflugmacher R, Scholz M, et al. Treatment of traumatic cervical spine instability with interbody fusion cages: a prospective controlled study with a 2-year follow-up. Injury 2005;36 Suppl 2:B2735.

17. Gallie WE. Fractures and dislocations of the cervical spine. Am J Surg 1939;46:495-9.

18. Hirabayashi K, Miyakawa J, Satomi K, Maruyama $\mathrm{T}$, Wakano K. Operative results and postoperative progression of ossification among patients with ossification of cervical posterior longitudinal ligament. Spine (Phila Pa 1976) 1981;6:354-64.

19. Rozzelle CJ, Aarabi B, Dhall SS, et al. Os odontoideum. Neurosurgery 2013;72 Suppl 2:159-69.

20. Grob D, Jeanneret B, Aebi M, Markwalder TM. Atlanto-axial fusion with transarticular screw fixation. J Bone Joint Surg Br 1991;73:972-6.

21. Brooks AL, Jenkins EB. Atlanto-axial arthrodesis by the wedge compression method. J Bone Joint Surg Am 1978;60:279-84.

22. Lowry DW, Pollack IF, Clyde B, Albright AL, Adelson PD. Upper cervical spine fusion in the pediatric population. J Neurosurg 1997;87:671-6.

23. Dickman CA, Sonntag VK. Posterior C1-C2 transarticular screw fixation for atlantoaxial arthrodesis. Neurosurgery 1998;43:275-80.

24. Farey ID, Nadkarni S, Smith N. Modified Gallie technique versus transarticular screw fixation in C1-C2 fusion. Clin Orthop Relat Res 1999;(359):126-35. 
25. Grob D, Crisco JJ 3rd, Panjabi MM, Wang P, Dvorak J. Biomechanical evaluation of four different posterior atlantoaxial fixation techniques. Spine (Phila Pa 1976) 1992;17:480-90.

26. Yoshida M, Neo M, Fujibayashi S, Nakamura T. Comparison of the anatomical risk for vertebral artery injury associated with the $\mathrm{C} 2$-pedicle screw and atlantoaxial transarticular screw. Spine (Phila Pa 1976) 2006;31:E513-7.
27. Sanelli PC, Tong S, Gonzalez RG, Eskey CJ. Normal variation of vertebral artery on CT angiography and its implications for diagnosis of acquired pathology. J Comput Assist Tomogr 2002;26:462-70.

28. Yukawa Y, Kato F, Yoshihara H, Yanase M, Ito K. Cervical pedicle screw fixation in 100 cases of unstable cervical injuries: pedicle axis views obtained using fluoroscopy. J Neurosurg Spine 2006;5:488-93. 